\title{
Controle de Estoque pelo Método de Curva ABC
}

Bacharelado em Ciências Contábeis pela Universidade Comunitária da Região de

Chapecó - UNOCHAPECÓ

E-mail: mateusruchel@unochapeco.edu.br

Daniela Di Domenico

Mestrado em Ciências Contábeis pela Universidade Regional de Blumenau - FURB Professora da Universidade Comunitária da Região de Chapecó - UNOCHAPECÓ Servidão Anjo da Guarda, 295-D. Efapi. Chapecó/SC. CEP: 89.809-900

E-mail: didomenico@unochapeco.edu.br

Jeancarlo Zuanazzi

Mestrado em Administração pela Universidade Regional de Blumenau - FURB Professor da Universidade Comunitária da Região de Chapecó - UNOCHAPECÓ

Servidão Anjo da Guarda, 295-D. Efapi. Chapecó/SC. CEP: 89.809-900 E-mail: zuanazzi@unochapeco.edu.br

Herivelton Antonio Schuster

Mestrado em Ciências Contábeis pela Universidade Regional de Blumenau - FURB Professor da Universidade Comunitária da Região de Chapecó - UNOCHAPECÓ Servidão Anjo da Guarda, 295-D. Efapi. Chapecó/SC. CEP: 89.809-900 E-mail: herivelton.schuster@unochapeco.edu.br

\section{RESUMO}

O presente trabalho teve como objetivo identificar como ocorre o controle de estoque, utilizando o método de curva $A B C$ em uma empresa do setor automobilístico. Para tanto, estudou-se uma indústria situada na região de Chapecó-SC do setor automobilístico. A metodologia foi desenvolvida visando melhorar e otimizar seu processo sem desperdício e custos irrelevantes. Na referida empresa foi possível verificar problemas no processo de gerenciamento do estoque e alocação dos itens que possuíam regra de rotatividade e da compra dos itens para a reposição. Utilizou-se como metodologia a curva $A B C$, que é extremamente vantajosa, a fim de separar os itens de maior, média e menor importância, assim como a demanda valorizada, classificando-os de forma proporcional ao seu retorno financeiro à empresa. O resultado deste estudo aponta que o item com maior rotatividade no estoque da empresa foi o óleo lubrificante, utilizado diariamente, seguido por outros itens agregados ao óleo. Já na curva B o destaque é a vela de ignição com moderada rotatividade; e, na curva C, apresentam-se peças de menor importância para a empresa, como retentores e palhetas. $O$ item de maior valor agregado é o jogo de embreagem. De forma geral, destaca-se a importância da ferramenta $A B C$ na gestão e controle do estoque de uma instituição. Com o auxílio da curva pode-se estabelecer prioridades de compras e vendas, disponibilizando os recursos financeiros adequadamente. 
Análise de Custos em uma Instituição de Ensino Superior: um Estudo Aplicado no Instituto

Federal do Tocantins

Samara Oliveira Alves, William Brasil Rodrigues Sobrinho

Palavras-chave: Controle de estoque. Curva ABC. Otimização. Rotatividade.

Stock Control by ABC Curve Method

\section{ABSTRACT}

The present study aimed to identify how inventory control occurs withABC curve method in an automotive sector company located in Chapecó-SC region. The methodology was developed in order to optimize this company's profit by highlightingirrelevant costs and waste of time, as found in the inventory management process and allocation of items, which did not have a rotation rule, as well as the purchase of items for replacement. The ABC curve was used as methodology, in order to separate the items of greater, medium, and less importance and valued demand, and for classifying them proportionally to their financial return to the company. The result of this study points out that the item with the highest turnover in the company's stock was the lubricating oil, used daily, placed in curve A and followed by other items added to the oil; in curve B the highlight is the spark plug with medium rotation; and, in curve $C$, the parts of less importance for the company are presented, such as retainers and reeds. The item with the highest added value was found to be the clutch kit. The importance of the ABC tool in the management and control of an institution's stock stands out. With the aid of the curve, it is possible to establish purchasing and sales priorities, making financial resources available accordingly.

Keywords: Inventory control. ABC curve. Optimization. Turnover.

Control de Stock por Método de Curva ABC

\section{RESUMEN}

El presente estudio tuvo como objetivo identificar cómo se produce el control de inventario, utilizando el método de la curva $A B C$ en una empresa del sector automotriz. Con este fin, se estudió una industria ubicada en la región Chapecó-SC del sector automotriz. La metodología fue desarrollada para mejorar y optimizar su proceso sin desperdicio y costos irrelevantes. En esa empresa hubo problemas en el proceso de gestión de inventario y asignación de artículos, que tenía una regla de rotación, y la compra de artículos para su reemplazo. La curva $A B C$ se utilizó como metodología, lo cual es extremadamente ventajoso, con el fin de separar los elementos de mayor, mediana y menor importancia y demanda valorada, clasificándolos proporcionalmente a su rendimiento financiero para la empresa. El resultado de este estudio señala que el artículo con el mayor volumen de ventas en las existencias de la compañía fue el aceite 
lubricante, usado diariamente, y seguido de otros artículos agregados al aceite. En la curva $B$, lo más destacado es la bujía con rotación moderada; y, en la curva $C$, se presentan partes de menor importancia para la empresa, como los retenedores y las cañas. El artículo con el mayor valor agregado es el kit de embrague. En general, se destaca la importancia de la herramienta $A B C$ en la gestión y el control de las acciones de una institución. Con la ayuda de la curva, se pueden establecer prioridades de compra y venta, haciendo que los recursos financieros estén disponibles en consecuencia.

Palabras clave: Control de inventario. Curva ABC. Mejoramiento. Rotación.

\section{INTRODUÇÃO}

Quando se fala em gestão de empresas, destaca-se a forma de gerenciar a organização como um todo. Tratando-se de gestão e de ferramentas de estoque, consideram-se os estoques como custos e algumas vezes embaraçam grande quantidade do capital da instituição quando não gerenciados de forma correta. Além disso, são arriscados, uma vez que os itens mantidos em estoque podem se deteriorar e tornarem-se obsoletos, ocupando espaços que poderiam ser usados para a produção. Em contrapartida, proporcionam certa segurança em um ambiente complexo e incerto (Rabelo \& Ventura, 2018).

A gestão de estoques relaciona-se diretamente à lucratividade da empresa, pois o administrador precisa garantir o giro cada vez mais rápido das mercadorias, sem colocar em risco o abastecimento das linhas de produção e o atendimento aos pedidos. Nesse sentido, a redução dos níveis de estoque ganha relevância, visto que os custos para a manutenção dos estoques são elevados (Gustavo, Domingos, \& Terra, 2013).

Quando não há controle de estoque, a empresa pode ser financeiramente prejudicada: a ausência de informações precisas e a falta de controle não permitem saber a quantidade existente no estoque, ou seja, pode causar prejuízos tanto na perda de produtos acabados quanto na venda para clientes (Rabelo \& Ventura, 2018).

Manter estoques e não possuir controles definidos e eficientes para gerenciá-los pode tornar-se um grande problema para as empresas, visto que estoque inerte é 
Análise de Custos em uma Instituição de Ensino Superior: um Estudo Aplicado no Instituto Federal do Tocantins

Samara Oliveira Alves, William Brasil Rodrigues Sobrinho

dinheiro que deixa de ser aplicado, o que pode gerar dificuldades na administração do fluxo de caixa das empresas. O gerenciamento de estoques é imprescindível às organizações, uma vez que viabilizam a economia de recursos e o constante atendimento das necessidades dos clientes (Godinho, Canaldi, Garbin, \& Dutra, 2018).

Uma alternativa para o gerenciamento do estoque é a Curva $A B C$, que permite a identificação de problemas na gestão de estoques, possibilitando a redução de custos. Quando utilizada no gerenciamento de estoques, a Curva $A B C$ abrange todos os itens que o compõe: principais, intermediários e menos importantes, viabilizando redução de custos e melhoria no gerenciamento (Melo \& Saito, 2016).

Como mencionado anteriormente, a curva $A B C$ é um importante instrumento para o administrador a qual permite identificar itens que justificam atenção, dar tratamento adequado para compras e vendas de itens com maior giro na empresa, e reorganização de estoque, realocando itens de maior rotatividade, podendo assim otimizar o tempo de separação e conferência de mercadorias (Lyra \& Lazer, 2017).

Dentro dessa perspectiva, a pergunta que norteia o desenvolvimento da pesquisa é: Como se dá o controle de estoque a partir do método de curva $A B C$ ? Com intuito de responder à pergunta, o objetivo do presente estudo é identificar como ocorre o controle de estoque, utilizando o método de curva $A B C$ em uma empresa do setor automobilístico.

$\mathrm{Na}$ referida empresa foram observados problemas em relação aos métodos utilizados para a gestão de estoque, dado que a alocação dos itens não tem uma regra de rotatividade, juntamente com compra de itens para a reposição do estoque. Conforme abordado no trabalho, a curva $\mathrm{ABC}$ permite que sejam estabelecidas metas $\mathrm{e}$ se tenha foco diante de situações que possam comprometer o orçamento de uma empresa e até mesmo comprometer a prestação de um serviço.

Ao longo do trabalho, além do tópico introdutório, abordou-se na revisão de literatura o controle de estoque, o método de curva abc e alguns estudos correlatos selecionados que serviram de base para o desenvolvimento do trabalho. Ainda, nos procedimentos metodológicos, descreveu-se como foram realizadas as pesquisas e 
Análise de Custos em uma Instituição de Ensino Superior: um Estudo Aplicado no Instituto Federal do Tocantins Samara Oliveira Alves, William Brasil Rodrigues Sobrinho

aplicações do método de curva $A B C$ no estoque da empresa automobilística de Chapecó-SC. Por fim, a análise dos resultados e as considerações finais.

\section{REVISÃO DA LITERATURA}

Neste tópico, abordam-se os controles de estoques, os sistemas de controle financeiro que ajudaram a organizar a empresa; método de curva $A B C$ é um sistema de controle cujo objetivo é determinar quais são os produtos mais importantes de uma empresa; e estudos correlatos, que apresentarão exemplos de pesquisas elaboradas e relacionadas ao tema e seus resultados.

\subsection{Controle de Estoque}

Empresas buscam sempre ferramentas que auxiliem suas gestões, independente do ramo ou da atividade, é importante ter métodos eficazes de controle de estoque, já que quanto menor o custo em compras e manutenção de estoques, maior será o lucro da empresa no período (Rodrigues \& Carreira, 2018).

$O$ estoque é definido como qualquer quantidade de bens físicos que sejam conservados de forma produtiva ou improdutiva por determinado período. Eles podem ser constituídos tanto de matéria-prima e componentes que aguardam para serem utilizados no processo produtivo, ou produtos acabados que a aguardam venda e despacho (Rabelo \& Ventura, 2018).

Faz-se necessário uma visão micro e macroeconômica, onde se observa a situação que se encontra o mercado, podendo ter uma previsão futura, sendo ela positiva ou não. Pensando dentro da gestão de estoque pode significar produzir em maior quantidade, consequentemente, elevando os custos ou produzir em menor quantidade, correndo o risco de não conseguir atender uma demanda eventualmente mais elevada (Lemes \& Lima 2018).

Atender a demanda do mercado, tendo produtos disponíveis, sem onerar excessivamente o caixa da empresa, é um desafio para os gestores de estoques. 
Análise de Custos em uma Instituição de Ensino Superior: um Estudo Aplicado no Instituto Federal do Tocantins

Samara Oliveira Alves, William Brasil Rodrigues Sobrinho

Procurando atender esse objetivo, a administração de estoques deve envolver a manutenção de índices de estoque tão baixo quanto o possível e ao mesmo tempo prever a disponibilidade desejada pelos clientes. É preciso que os gestores compreendam as reais necessidades dos pedidos e qual o método adequado para o gerenciamento dos estoques, reduzindo custos, eliminando gastos e elevando a margem de lucro (Rego, 2017).

O custo de manutenção do estoque pode representar $20 \%$ a $40 \%$ de seu valor por ano e, por isso, administrá-lo cuidadosamente economicamente sensato. O elevado nível de estoques pode trazer diversos problemas, como atraso na entrega por parte dos fornecedores, baixa previsibilidade da demanda, e lead time desajustado. Em função desses custos, é importante que os gestores evitem níveis elevados. O objetivo da administração de estoque é girá-lo o mais rápido possível sem perder vendas por falta de estoque (Lemes \& Lima 2018).

O estoque deve ser entendido como importante ferramenta, cujo objetivo é garantir a estabilidade do sistema de produção. "Esta ferramenta envolve um custo, consequentemente, deve ser mantida em níveis mínimos, mas não a ter pode ser perigoso para o funcionamento da organização" (Pinto, Tortato, Veiga, \& Catapan, 2013).

$\mathrm{O}$ aumento das vendas requer investimentos marginais em estoques para que a empresa consiga atender a demanda prevista. Entretanto, essa decisão revela resultados contraditórios, uma vez que estudos apontam que a moeda incremental, investida em crédito para os clientes, tem um efeito muito maior na riqueza do acionista do que a moeda incremental investida em estoque, sugerindo assim, que a política de crédito é uma política importante na gestão de capital de giro (Carvalho, 2015).

Quanto maior o estoque, maior será seu custo de manutenção, no entanto, menor será a necessidade de pedidos, com maiores lotes para manter os níveis de inventário. Lotes maiores implicam menores custos de aquisição e de falta. Portanto, há autores que afirmam que o custo de estoque é uma questão de balancear os custos de manutenção, aquisição e falta dos mesmos (Rabelo \& Ventura, 2018). 
Análise de Custos em uma Instituição de Ensino Superior: um Estudo Aplicado no Instituto Federal do Tocantins

Samara Oliveira Alves, William Brasil Rodrigues Sobrinho

Manter e gerenciar estoques requer não apenas espaço físico, mas também funcionários para manusear e administrar, além de equipamentos específicos ou máquinas que podem acarretar gastos relevantes. Em função disso, criaram-se as diversas ferramentas capazes de auxiliar os gestores a controlar os volumes de estoque, entre os quais, cita-se: a Curva $A B C$ de estoques, Lote Econômico de Compra, Ponto de Pedido, entre outros (Wernke, Zanin, Schlickmann, \& Santos, 2017).

A função do controle é definida como um fluxo de informações que permite comparar o resultado real de determinada atividade, com seu resultado planejado e, ainda, otimizar o investimento, aumentando o uso eficiente com meios internos a fim de minimizar a necessidade de capital investido em estoques, reduzindo prejuízos e desperdícios (Falchi, Francischetti, \& Lima, 2014).

\subsection{Método de Curva ABC}

O princípio da curva $A B C$ foi elaborado por Vilfredo Pareto, na Itália, no final do século passado. Foi feito um estudo de distribuição de renda e riqueza da população local por volta do ano de 1897 e, neste estudo, Pareto identificou que grande porcentagem da renda total se concentrava nas mãos de uma pequena parcela da população, em uma proporção de aproximadamente $80 \%$ e $20 \%$ respectivamente, ou seja, $80 \%$ da riqueza local estava concentrada com $20 \%$ da população. A partir de então, tal princípio de análise tem sido estendido a outras áreas e atividades, tais como a industrial e a comercial, sendo mais amplamente aplicado a partir da segunda metade do século XX (Rabelo \& Ventura, 2018).

A utilização da curva $A B C$ é extremamente vantajosa, todavia, pode-se reduzir as imobilizações em estoque sem prejudicar a segurança, já que ela controla mais rigidamente os itens de classe $\mathrm{A}$ e, mais superficialmente, os de classe $\mathrm{C}$. Rabelo e Ventura ainda afirmam que a curva $A B C$ é assim chamada em razão de dividir os dados obtidos em três categorias distintas, denominadas classe A, B e C (Rabelo \& Ventura, 2018). 
Análise de Custos em uma Instituição de Ensino Superior: um Estudo Aplicado no Instituto Federal do Tocantins

Samara Oliveira Alves, William Brasil Rodrigues Sobrinho

$\mathrm{Na}$ classe A estão os itens mais importantes e que devem receber toda atenção no momento inicial do estudo; na classe B, estão itens intermediários e que deverão ser tratados logo após as medidas tomadas sobre os itens de classe A; e, na classe C, estão os itens de menor importância, embora volumosos em quantidade, possuem valor monetário reduzido, permitindo maior espaço de tempo para sua análise e tomada de ações (Rabelo \& Ventura, 2018).

A curva $A B C$ baseia-se nas teorias econômicas do italiano Vilfredo Paretto, e trata-se de um método de classificação de informações a fim de se separar os itens de maior importância. A partir disso, os mesmos são tratados como prioridade, por apresentar maior demanda valorizada (Wescinski, 2017). Conforme Da Silveira (2018), a curva $A B C$ visa o controle de estoques de componentes, classificando-os de maneira proporcional ao seu retorno financeiro na empresa, conforme a Figura 1.

\begin{tabular}{|l|l|l|}
\hline \multicolumn{1}{|c|}{ Classe A } & \multicolumn{1}{|c|}{ Classe B } & \multicolumn{1}{|c|}{ Classe C } \\
\hline Destina-se ao grupo de tens & $\begin{array}{l}\text { Trata-se do grupo de itens em } \\
\text { relevantes da curva que }\end{array}$ & $\begin{array}{l}\text { Refere-se ao grupo de itens de menor } \\
\text { importância, que detém pouca atenção }\end{array}$ \\
devem ser tratados com & Classes A e C. Corresponde & por parte da administração. \\
atenção especial pela & aproximadamente 30\% dos & Corresponde aproximadamente 50\% \\
administração corresponde & itens e 20\% do valor das & dos itens e 10\% do valor das vendas. \\
aproximadamente a 20\% dos & vendas. & \\
itens e 70\% do valor das & & \\
vendas. & & \\
\hline
\end{tabular}

Figura 1. Classificação das classes $A B C$

Fonte: Silveira (2018).

A classificação típica do estoque apresenta uma configuração onde $20 \%$ dos itens são considerados classe A, $30 \%$ classe B e os outros $50 \%$ classe C. Não existe uma regra fixa para determinar esse ranking, uma vez que em cada organização esses valores podem variar. Assim, deve-se comtemplar a regra 80/20, também conhecida como Princípio de Pareto, que aproximadamente $20 \%$ de qualquer recurso respondem por $80 \%$ das atividades relacionadas a esses recursos (Rodrigues \& Carreira, 2018). 
Análise de Custos em uma Instituição de Ensino Superior: um Estudo Aplicado no Instituto Federal do Tocantins Samara Oliveira Alves, William Brasil Rodrigues Sobrinho

\subsection{Estudos Correlatos}

Os artigos que serão apresentados nessa seção foram analisados e ajudaram a compor o artigo corrente. Eles estão dispostos em ordem crescente de acordo com o ano de publicação, com uma breve explanação de cada trabalho escolhido, totalizando seis análises.

Vago, Sousa e Melo (2013) identificaram como a utilização da ferramenta curva $A B C$ pode contribuir com a gestão de almoxarifado de um Centro de Pesquisa Federal. A pesquisa mostrou que o almoxarifado possui 526 itens no estoque, os quais foram classificados por meio da curva $A B C$, considerando a quantidade de movimentações de cada um durante o ano. Assim, conheceu-se a quantidade existente de cada item dentro das respectivas classes com relação a sua quantidade movimentada. Verificouse que, $78 \%$ da movimentação total, em 2011 , corresponde a $13 \%$ da quantidade total de itens no estoque. Na classe A, 67 materiais foram identificados, podendo ser considerados como os mais importantes para a instituição. A classe B corresponde a $17 \%$ das movimentações e a $25 \%$ da quantidade total de itens, totalizando 131 materiais. Já os itens que podem ser considerados como classe $\mathrm{C}$, correspondem à apenas $5 \%$ da quantidade de movimentações, porém, representam $62 \%$ de todo o estoque, totalizando 328 materiais. Os resultados indicam que a curva $A B C$ permitiu que os gestores visualizassem melhor o estoque, estabelecendo políticas de controle mais precisas, já que é mais saudável não tratar todos os itens da mesma forma.

Lyra e Lazer (2017) avaliaram 274 itens do estoque que possuíam maior rotatividade, tais como os itens de consumo diário que são necessários para a prestação dos serviços que a empresa oferece. Muitos itens do estoque não foram avaliados por estarem há muito tempo sem nenhum giro, tornando-se, após determinado período, itens obsoletos. Concluiu-se que com a aplicação da curva $A B C$ torna-se possível identificar quais itens exigem maior atenção, possibilitando que a gerência tome decisões em relação ao consumo, assim, reduzindo custos e evitando desperdícios. Ainda, a ferramenta pode ser utilizada para otimizar o espaço físico, 
Análise de Custos em uma Instituição de Ensino Superior: um Estudo Aplicado no Instituto Federal do Tocantins

Samara Oliveira Alves, William Brasil Rodrigues Sobrinho

reduzir custos e analisar minuciosamente todos os itens que devem ser mantidos em estoque.

O estudo realizado por Da Silveira (2018) analisou o dimensionamento do estoque obsoleto de uma concessionária de caminhões. Com base no relatório gerado pelo software da empresa, identificou-se que das 4.398 peças registradas, 2.614 estavam obsoletas. Assim, 59,40\% do estoque encontra-se obsoleto, o que evidencia que a empresa tem um prejuízo de $\mathrm{R} \$ 348.956,00$, sendo um valor significativo de dinheiro parado, que ainda envolve custos de armazenamento. Após a verificação dos valores encontrados, os gerentes redimensionaram lotes de peças e se desfizeram de certa quantia, reduzindo assim o número de peças paradas. Após três meses da primeira verificação, indicaram a construção da segunda curva para novamente verificar a situação do estoque. O estudo contribuiu para levantar os dados do real prejuízo da empresa, que conseguiu ter melhor controle sobre a situação, identificando quais peças estavam obsoletas e agindo no sentido de reduzir esse número.

A pesquisa de Oliveira (2018) analisou as ferramentas de gestão utilizadas no controle de estoque e logística de medicamentos da Central de Abastecimento Farmacêutico do Hospital das Clínicas da Universidade Federal de Minas Gerais. Foi proposto um modelo de gestão utilizando a ferramenta estratégica Kanban e a curva $A B C$ de Pareto, visando redução de custo e organização dos estoques de forma a contribuir com a gestão de materiais e logística de medicamentos. Apresentou-se como resultado que, na situação apresentada, todas as classes estão dentro do padrão proposto de gestão da curva $A B C$, significando que os itens da classe $A$ representam o custo mais robusto e por isso são de maior importância dentro do HC-UFMG. Assim, o não abastecimento desses itens pode comprometer o funcionamento do hospital. Da mesma forma, o aumento do consumo ou do preço pode impactar os investimentos necessários para reposição e gerenciamento do estoque desse item. Já os itens da classe B representam uma classe intermediária, e os da classe C itens de menor importância. 
Análise de Custos em uma Instituição de Ensino Superior: um Estudo Aplicado no Instituto Federal do Tocantins Samara Oliveira Alves, William Brasil Rodrigues Sobrinho

O estudo de Teixeira (2018) descreve o modelo de gestão de estoque de peças de concessionárias de automóveis. Para demonstrar a construção de uma curva $A B C$ o autor utilizou 10 itens, onde utilizou como critério de ordenação o valor do consumo anual para cada item. Com base na curva $A B C$, destaca-se que determinados itens merecem mais atenção por parte do departamento para aplicação de controles mais eficientes e capital investido. Assim como, deve existir uma gestão de estoque de acordo com a classificação $A B C$, a qual é de grande importância para o sucesso da administração. Essa classificação serve para identificar quais os produtos prioritários na demanda do mercado.

Oliveira (2018) demonstrou a aplicação da classificação ABC no estoque de uma microempresa de autopeças e sua importância para a tomada de decisões dos gestores. Com base na relação de produtos vendidos no ano de 2011 e considerando o preço de custo dos mesmos, os autores elaboraram uma classificação da curva $A B C$ dos produtos para a empresa. Os resultados indicam que existe uma elevada concentração de produtos no setor de estoque que não são considerados itens de grande importância e apresenta baixo fluxo no giro do estoque, situação que é desfavorável para a empresa, visto que pode ocasionar prejuízos ou dificuldades no gerenciamento do estoque.

Com base nos estudos correlatos realizados percebe-se que cada autor trata do funcionamento dos estoques de maneira que busca a solução das deficiências na organização. Procurando saber a dimensão do estoque obsoleto, e quais as ferramentas de gestão que podem ser usadas para solucionar e controlar o estoque e a logística, e com a curva $A B C$, pode-se tornar possível a identificação de itens que exigem atenção, possibilitando, em relação ao consumo, a redução de custos e evitando desperdícios.

Com o objetivo de analisar o impacto da gestão das práticas de oferta de crédito sobre a de estoques, em micro e pequenas empresas, conclui-se que a gestão das práticas de estoque sofre influência tanto pela disponibilidade de recursos financeiros quanto pelo nível de receitas planejado (Carvalho, 2015). 
Análise de Custos em uma Instituição de Ensino Superior: um Estudo Aplicado no Instituto Federal do Tocantins Samara Oliveira Alves, William Brasil Rodrigues Sobrinho

\section{PROCEDIMENTOS METODOLÓGICOS}

O trabalho corrente questiona: Como se dá o controle de estoque utilizando o método de curva $A B C$ ? Analisou-se quais os itens do estoque são classificados como $A$, que são de maior rotatividade; $B$, onde se encontram os itens que possuem uma menor rotatividade; e no $C$, que são os produtos de menor importância, já que não se constituem de vendas mensais. Tomou-se como objetivo demostrar a eficiência de possuir um método de gestão de estoques, a importância de se ter informações precisas através desse método, assim, apresentando à empresa do ramo automobilístico em questão, situada em Chapecó, região oeste de Santa Catarina, possibilidades para ela alcançar seus melhores resultados.

O estudo foi realizado, quanto aos objetivos, na forma de pesquisa exploratória, analisando a rotatividade e lucratividade dos itens no estoque, buscando uma maior familiaridade com o problema, deixando-o mais claro. O procedimento adotado foi o estudo de caso, no qual se analisou o fluxo do estoque da empresa, analisando documentos/relatórios que serão trazidos sobre o funcionamento da curva $A B C$ depois de sua implantação.

Acerca do estudo de caso como procedimento adotado, justifica-se uma vez que essa modalidade de pesquisa faz uma análise profunda e exaustiva de um ou de poucos objetos, de modo a permitir o seu conhecimento amplo e detalhado em desenhos caracterizados pela flexibilidade, simplicidade de procedimentos e ênfase na abordagem qualitativa integral dos eventos. Ainda, a pesquisa caracteriza-se como um estudo de caso por tomar forma em uma única empresa e suas conclusões circunscreverem-se ao contexto do objeto estudado (Wernke et al., 2017).

A empresa onde foi realizada a pesquisa atua na região oeste de Santa Catarina, localizada na cidade de Chapecó desde 1947. A empresa precisou mudar de endereço devido aos problemas ambientais e por normas da marca que ela representa. Atualmente está localizada na saída de Chapecó em que tem sua matriz instalada e possui duas filiais onde atua no ramo do comércio de vendas de carros novos e 
Análise de Custos em uma Instituição de Ensino Superior: um Estudo Aplicado no Instituto Federal do Tocantins

Samara Oliveira Alves, William Brasil Rodrigues Sobrinho

seminovos, peças e serviços. Nos dias correntes a empresa é composta por 44 funcionários diretos.

Quanto à abordagem do problema, a pesquisa pode ser classificada como uma pesquisa qualitativa, pois visa analisar e quantificar, por meio de uma lista de checagem, os itens estocados pela empresa de acordo com a metodologia ABC. A respeito da forma de abordagem do problema pode ser considerada como qualitativa, pois é concebido análises mais aprofundadas em relação ao fenômeno que está sendo estudado, visando destacar características que não são passíveis de serem observadas através de um estudo quantitativo. Nesse sentido, denominam-se de "qualitativos" os estudos que podem descrever a complexidade de determinado problema, analisar a interação de certas variáveis, e, ainda, compreender e classificar processos dinâmicos vividos por grupos sociais (Wernke et al., 2017).

A coleta de dados foi realizada por meio do sistema informatizado e histórico de compras e vendas da empresa, ou seja, por meio de banco de dados da própria empresa, o que viabiliza a quantificação dos resultados, classificando os itens conforme a metodologia $A B C$ com base na lista de checagem utilizada para a coleta dos dados, onde foi coletado os códigos das peças, descrição, quantidade em estoque, custo unitário e custo total. A coleta foi realizada juntamente com o auxílio do sistema informatizado da empresa, o estoque apresentado é o total que girou no ano da análise, o custo unitário contém os impostos embutidos e o custo total é a multiplicação do custo unitário com a quantidade do item.

A pesquisa foi realizada através de visitas para a coleta de dados, utilizando como base o ano de 2018, e, posteriormente, foram analisados os documentos extraídos via sistema da empresa. Para a coleta dos dados, utilizou-se o sistema em que a empresa opera, o qual é contratado de uma outra empresa e o nome do sistema é Dealer. Foram parametrizados os seguintes dados no sistema, tais como o código do item, descrição, quantidade de vendas no ano de 2018, custo unitário e custo total. Após ser extraído o relatório, iniciou-se a análise dos dados dos itens que tiveram a maior rotatividade na empresa para que pudessem ser realocados no estoque de forma 
Análise de Custos em uma Instituição de Ensino Superior: um Estudo Aplicado no Instituto Federal do Tocantins Samara Oliveira Alves, William Brasil Rodrigues Sobrinho

que possa otimizar o tempo do almoxarife e através do método de curva $A B C$ pode-se ter uma melhor análise. Esses foram coletados e posteriormente tratados e analisados por meio de planilha eletrônica de dados.

\section{ANÁLISE DOS RESULTADOS}

Neste tópico são apresentados os dados obtidos na pesquisa as tabelas com a curva $A B C$, onde apresentam-se os itens com maior, média e menor rotatividade no estoque da empresa. A análise dos resultados mostra outras tabelas, como a de produtos com maior custo na empresa, a partir de procedimentos prévios e posteriores da pesquisa.

No ano da pesquisa, com a contagem do estoque, que é realizada no final de todo ano, o estoque da empresa apresentava um total de 3.267 itens diferentes. A seleção dos itens nas tabelas se deu através dos relatórios obtidos das vendas no ano todo de 2018, e, com isso, os produtos de maior rotatividade se enquadraram na curva $A$, os de venda média foram alocados na curva $B$ e o restante dos produtos se enquadraram na curva $C$, de pouca rotatividade no estoque.

A Tabela 1 apresenta a curva de maior importância para a empresa, na qual se pode observar os itens de maior rotatividade (curva A). A tabela contém dados que foram extraídos a partir da pesquisa de campo. 
Análise de Custos em uma Instituição de Ensino Superior: um Estudo Aplicado no Instituto Federal do Tocantins Samara Oliveira Alves, William Brasil Rodrigues Sobrinho

Tabela 1

Dados Referentes à Curva $\mathrm{A}$

\begin{tabular}{|c|c|c|c|c|c|}
\hline Item & Descrição & Quantidade & Custo Unitário & $\mathrm{Cu}$ & stoTtotal \\
\hline MB5A/5W30/BA/ & Óleo lubrificante & 12.732 & $\mathrm{R} \$ 11,68$ & $\mathrm{R} \$$ & $148.709,96$ \\
\hline EM5G/6714/AA/ & Filtro Lubrificante & 1.656 & $\mathrm{R} \$ 22,29$ & $\mathrm{R} \$$ & $36.912,24$ \\
\hline AM55/9155/AB/ & Filtro combustível & 1.502 & $\mathrm{R} \$ 29,55$ & $\mathrm{R} \$$ & $44.384,10$ \\
\hline FCSD/38907500/04/ & Fluido de freio & 989 & $\mathrm{R} \$ 14,57$ & $\mathrm{R} \$$ & $14.409,73$ \\
\hline 8V51/18D543/AA/ & Filtro pólem & 798 & $\mathrm{R} \$ 42,81$ & $\mathrm{R} \$$ & $34.162,38$ \\
\hline $81 \mathrm{AG} / 13466 / \mathrm{BA} /$ & Lâmpada & 746 & $R \$ 3,09$ & $\mathrm{R} \$$ & $2.305,14$ \\
\hline $81 \mathrm{AG} / 13465 / \mathrm{AA} /$ & Lâmpada & 689 & $\mathrm{R} \$ \quad 0,78$ & $\mathrm{R} \$$ & 537,42 \\
\hline 3890503 & Kit lubrificação & 632 & $\mathrm{R} \$ 18,97$ & $\mathrm{R} \$$ & $11.989,04$ \\
\hline $412356-0$ & Cinta plástica & 621 & $\mathrm{R} \$ \quad 0,78$ & $\mathrm{R} \$$ & 484,38 \\
\hline \multicolumn{4}{|c|}{ VALOR TOTAL DOS CUSTOS } & \multicolumn{2}{|c|}{$\mathrm{R} \$ 293.894,39$} \\
\hline
\end{tabular}

Nota. Fonte: Dados da pesquisa (2019).

A partir da Tabela 1, verifica-se que a curva A contém o código dos itens para a identificação de cada um, a descrição para auxiliar a interpretação dos dados, a quantidade de giro no estoque da empresa, o ano da realização da pesquisa, o custo unitário de cada item e o custo total para a aquisição dos produtos.

Analisando os itens na curva $A$, o item com maior rotatividade no estoque foi 0 "óleo lubrificante" com 12.737 litros, tendo que esse produto é utilizado diariamente e em todos os veículos que passam na oficina para a realização de revisões. Em segundo lugar, verifica-se o item "filtro lubrificante" com 1.656 unidades e, por terceiro, o produto "filtro de combustível" com 1.502 unidades. Nessa curva A, consegue-se observar que os itens que foram apresentados têm uma lógica envolvida que são itens essenciais para o ramo de atividade que a empresa está envolvida, pois são produtos que têm ligação de revisão veicular, como filtros, óleos, pastilhas de freio, velas de ignição, elementos, presilhas e cintas plásticas. A Tabela 2, a seguir, expõe dados inerentes à curva $\mathrm{B}$. 
Análise de Custos em uma Instituição de Ensino Superior: um Estudo Aplicado no Instituto Federal do Tocantins Samara Oliveira Alves, William Brasil Rodrigues Sobrinho

Tabela 2

Dados Referentes à Curva B

\begin{tabular}{|c|c|c|c|c|c|c|}
\hline \multirow{2}{*}{$\begin{array}{l}\text { Item } \\
\text { E3B1/1130/BA/ }\end{array}$} & \multirow{2}{*}{$\begin{array}{l}\text { Descrição } \\
\text { Velas Ignição }\end{array}$} & \multirow{2}{*}{$\frac{\text { Quantidade }}{86}$} & \multicolumn{2}{|c|}{ Custo Unitário } & \multicolumn{2}{|c|}{ Custo Total } \\
\hline & & & $\mathrm{R} \$$ & 36,62 & $\mathrm{R} \$$ & $3.149,32$ \\
\hline BE8Z/8124/A/ & Calota & 79 & $\mathrm{R} \$$ & 76,61 & $\mathrm{R} \$$ & $6.052,19$ \\
\hline 96BJ/13009/AA/ & Coxim Inferior & 79 & $\mathrm{R} \$$ & 9,01 & $\mathrm{R} \$$ & 711,79 \\
\hline E3B5/15A298/AB/ & Lâmpada & 78 & $\mathrm{R} \$$ & 23,13 & $\mathrm{R} \$$ & $1.804,14$ \\
\hline 7T4Z/9601/A/ & Porca & 78 & $\mathrm{R} \$$ & 9,13 & $\mathrm{R} \$$ & 712,14 \\
\hline CGSF/22/N/ & Elemento de ar & 74 & $\mathrm{R} \$$ & 59,53 & $\mathrm{R} \$$ & $4.405,22$ \\
\hline 95GP/18A886/AC/ & Velas Ignição & 74 & $\mathrm{R} \$$ & 22,33 & $\mathrm{R} \$$ & $1.652,42$ \\
\hline AYFS/32Y/R/ & Defletor superior & 73 & $\mathrm{R} \$$ & 113,78 & $\mathrm{R} \$$ & $8.305,94$ \\
\hline AYFS/22/CJ/ & Jogo embreagem & 72 & $\mathrm{R} \$$ & $2.464,69$ & $\mathrm{R} \$ 1$ & $177.457,68$ \\
\hline GU2J/9601/BA/ & Kit reparo & 71 & $\mathrm{R} \$$ & 71,05 & $\mathrm{R} \$$ & $5.044,55$ \\
\hline \multicolumn{3}{|c|}{ VALOR TOTAL DOS CUSTOS } & & & \multicolumn{2}{|c|}{$R$ \$ 209.295,39 } \\
\hline
\end{tabular}

Nota. Fonte: Dados da pesquisa (2019).

A Tabela 2 contém dados da curva $B$, sendo esses o código do item, a descrição dos produtos, a quantidades de cada item da curva, o custo unitário com impostos inclusos e o custo total dos itens na aquisição junto à fábrica.

$\mathrm{Na}$ curva B os itens intermediários que tiveram uma boa rotatividade. Na primeira linha, tem-se o item "vela de ignição" com 86 peças vendidas. Analisando que o valor dela é considerável ( $\mathrm{R} \$ 36.62$ por unidade) multiplicando com as oitenta e seis vendidas têm um montante de $R \$ 3.149,32$, tem-se também a "calota" que é comercializada principalmente para locadoras de veículos como o item dois, "calota", com 79 unidades vendidas no ano de 2018.

Pode-se identificar que na curva B os itens são mais diversificados que na curva A, pois são itens como calota, disco de freio, bateria, maçanetas, sensores, base de antenas, rolamentos, grades, defletores entre outros.

A seguir, a Tabela 3 expõe dados inerentes à curva $C$. 
Tabela 3

Dados Referentes à Curva C

\begin{tabular}{|c|c|c|c|c|}
\hline Item & Descrição & Quantidade & Custo Unitário & Custo Total \\
\hline W714040/S3/00 & Retentor & 29 & $\mathrm{R} \$ \quad 0,89$ & $\mathrm{R} \$ \quad 25,81$ \\
\hline DG9Z/2078/D/ & Protetor caçamba & 29 & $\mathrm{R} \$ 407,00$ & $\mathrm{R} \$ 11.803,00$ \\
\hline DG9Z/5493/G/ & Isolador & 29 & $\mathrm{R} \$ \quad 42,68$ & $\mathrm{R} \$ \quad 1.237,72$ \\
\hline DS7Z/54264A26/A/ & Para-choque diante & 28 & $\mathrm{R} \$ 443,79$ & $\mathrm{R} \$ 12.426,12$ \\
\hline 1225022 & Palhetas limpador & 28 & $\mathrm{R} \$ 124,26$ & $R \$ 3.479,28$ \\
\hline LRO176P & Palhetas limpador & 28 & $\mathrm{R} \$ 91,00$ & $R \$ 2.548,00$ \\
\hline BR3Z/18183/D/ & Emblema & 28 & $\mathrm{R} \$ \quad 47,70$ & $R \$ 1.335,60$ \\
\hline E3BZ/13408/H/ & Farol L/E & 27 & $\mathrm{R} \$ 579,06$ & $R \$ 15.634,62$ \\
\hline 1S7A/13009/DA/ & Lâmpada & 27 & $\mathrm{R} \$ 41,70$ & $\mathrm{R} \$ 1.125,90$ \\
\hline 2S65/14A169/BA/ & Roda aço & 26 & $\mathrm{R} \$ 226,02$ & $\mathrm{R} \$ 5.876,52$ \\
\hline
\end{tabular}

Nota. Fonte: Dados da pesquisa (2019).

$\mathrm{Na}$ Tabela 3 são apresentadas as peças com menor importância para a empresa, onde, na curva, apresentam-se os códigos de cada produto que girou na empresa no ano de 2018, as descrições de cada peça, valor de custo unitário e o custo total de cada produto.

$\mathrm{Na}$ teoria da curva $\mathrm{ABC}$, os itens que estão na curva $\mathrm{C}$ são compostos por itens que têm menor importância para o estoque da empresa, o que não corrobora para esta pesquisa, pois utiliza-se a curva $A B C$ para observar os produtos de maior rotatividade. $\mathrm{Na}$ curva $\mathrm{C}$ os itens que tiveram uma venda considerável para a empresa, como $\mathrm{o}$ item da primeira linha "retentor", que teve uma venda de 29 peças no ano de 2018 , com um custo unitário de $R \$ 0,89$ e um custo total de $R \$ 25,81$.

Após analisar as curvas $A B C$, identificou-se que na curva $A$ existem itens relacionados às revisões, e que, consequentemente, são vendidos todos os dias, como: filtro de óleo, óleo, filtro de combustível, filtro pólem, velas, entre outros itens. Já na curva $B$, os itens são mais diversificados, pois é onde se encontram os itens mais 
Análise de Custos em uma Instituição de Ensino Superior: um Estudo Aplicado no Instituto Federal do Tocantins Samara Oliveira Alves, William Brasil Rodrigues Sobrinho

diversos, como para-choques, velas, pastilhas, cintas; e na curva $C$, são os itens de menor importância para a empresa ou que não possuem grande giro.

A Tabela 4, a seguir, destaca os dados de itens com maiores valores.

Tabela 4

Itens com maior valor

\begin{tabular}{|c|c|c|c|c|}
\hline Item & Descrição & Quantidade & Custo Unitário & Custo Total \\
\hline E3B1/1130/BA/ & Jogo embreagem & 72 & $\mathrm{R} \$ 2.464,69$ & $\mathrm{R} \$ 177.457,68$ \\
\hline MB5A/5W30/BA/ & Óleo lubrificante & 12.732 & $\mathrm{R} \$ 11,68$ & $\mathrm{R} \$ 148.709,76$ \\
\hline CN1Z/99264A26/A/ & Kit fechadura & 142 & $\mathrm{R} \$ 820,09$ & $\mathrm{R} \$ 116.452,78$ \\
\hline BE8Z/8124/A/ & Módulo & 38 & $\mathrm{R} \$ 2.407,11$ & $\mathrm{R} \$ 91.470,18$ \\
\hline $96 \mathrm{BJ} / 13009 / \mathrm{AA} /$ & Jogo embreagem & 41 & $\mathrm{R} \$ 2.160,65$ & $\mathrm{R} \$ 88.586,65$ \\
\hline 2S65/3R700/BF/ & Kit fechadura & 114 & $\mathrm{R} \$ 671,09$ & $\mathrm{R} \$ 76.504,26$ \\
\hline E3B1/2001/AB/ & Pastilha de freio & 298 & $\mathrm{R} \$ 227,52$ & $\mathrm{R} \$ 67.800,96$ \\
\hline AB39/9176/AC/ & Filtro combustível & 341 & $\mathrm{R} \$ 173,28$ & $\mathrm{R} \$ 59.088,48$ \\
\hline AB31/2L361/AB/ & Pastilha de freio & 132 & $\mathrm{R} \$ 397,67$ & $\mathrm{R} \$ 52.492,44$ \\
\hline AM55/9155/AB/ & Filtro combustível & 1.502 & $\mathrm{R} \$ 29,55$ & $\mathrm{R} \$ 44.384,10$ \\
\hline AV61/2K021/BB/ & Pastilha de freio & 103 & $\mathrm{R} \$ 393,77$ & $\mathrm{R} \$ 40.558,31$ \\
\hline
\end{tabular}

VALOR TOTAL DOS CUSTOS

$\mathbf{R} \$ \mathbf{9 6 3 . 5 0 5 , 6 0}$

Nota. Fonte: Dados da pesquisa (2019).

$\mathrm{Na}$ Tabela 4, apresentam-se os itens com maior custo de aquisição na empresa, com os códigos de produto, descrição, quantidade, custo unitário e custo total. Os códigos de cada item são fornecidos pela fábrica juntamente com a descrição de cada item.

Os valores das curvas $A$ têm um total de $R \$ 1.096 .151,22$, pela qual passaram 32.091 itens pelo estoque, na curva $B$ têm-se um total de 3.132 peças com um valor total de $\mathrm{R} \$ 718.995,47$ e, na curva $\mathrm{C}$, passou pelo estoque 1.202 unidades e um valor de $R \$ 295.802,98$. Nessa planilha, verificam-se as peças que tiveram o maior desembolso para a aquisição, totalizando $R \$ 1.203 .925,90$ com itens das curvas $A$ e $B$. Como esses itens têm uma rotatividade anual grande e sempre terá uma boa quantidade de unidades disponível para atender os clientes. 
Análise de Custos em uma Instituição de Ensino Superior: um Estudo Aplicado no Instituto Federal do Tocantins Samara Oliveira Alves, William Brasil Rodrigues Sobrinho

O fluxo dos produtos demostra como é realizado o pedido das peças, recebimento das mercadorias junto à transportadora, conferência dos itens, alocação dos itens nas prateleiras do estoque, o atendimento de vendas, separação, conferência e entrega do produto. Nesse sentido, a Figura 2 dispõe de dados inerentes ao fluxo de produtos no ano de 2018.

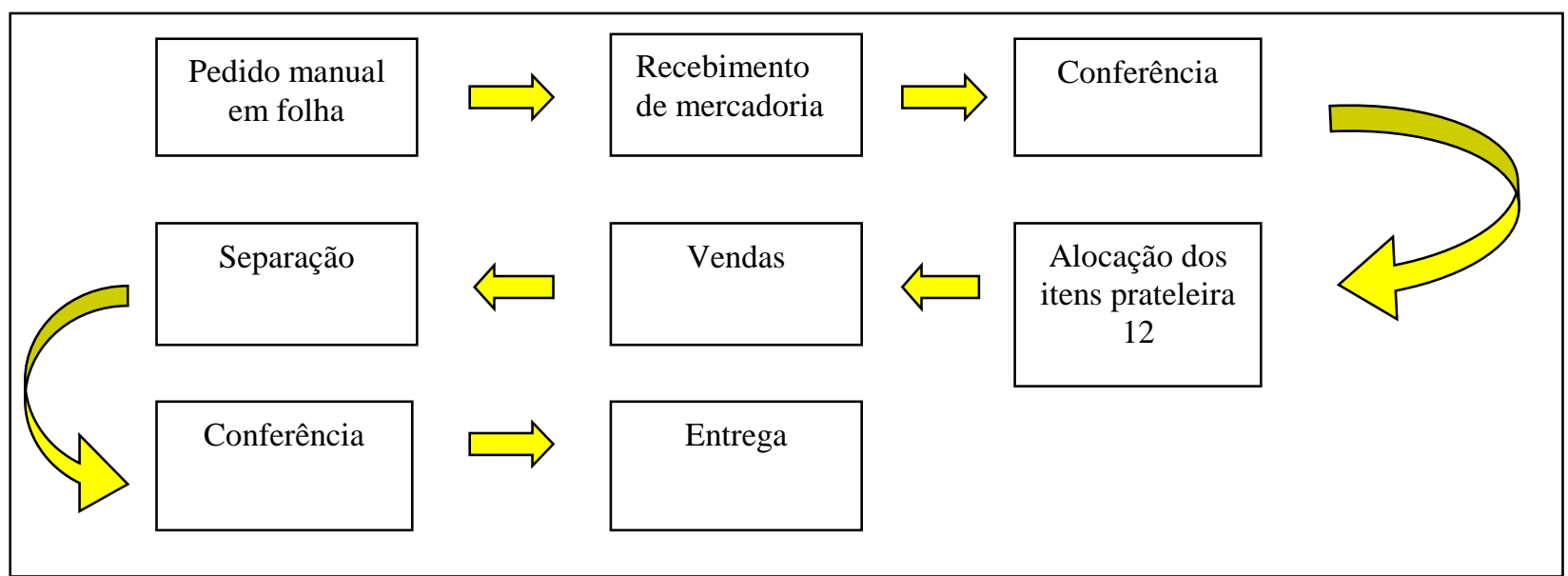

Figura 2. Fluxo dos Produtos em 2018.

Fonte: Dados da pesquisa (2019).

Visualiza-se, a partir do exposto na Figura 2, o procedimento de pedido, conferência, alocação e vendas dos itens. Antes de realizar esta pesquisa, o procedimento de peças era efetuado todo manualmente. Sendo que o pedido de peças era realizado pelo vendedor ou estoquista por folha de oficio, onde constavam os dados dos clientes, veículo e dados das peças, ainda, a conferência das mercadorias era efetuada manualmente através de uma requisição de entrada das notas fiscais. Após a conferência era efetuado a alocação do item em uma prateleira que estava vaga, como na tabela "Figura 2" em que o item entra na prateleira 12. Após o vendedor efetuar a sua venda, era tirado um pedido de separação, onde constava os dados do item e sua alocação, o estoquista então separava o item na prateleira 12, realizava a conferência e a entrega do produto. 
Análise de Custos em uma Instituição de Ensino Superior: um Estudo Aplicado no Instituto Federal do Tocantins Samara Oliveira Alves, William Brasil Rodrigues Sobrinho

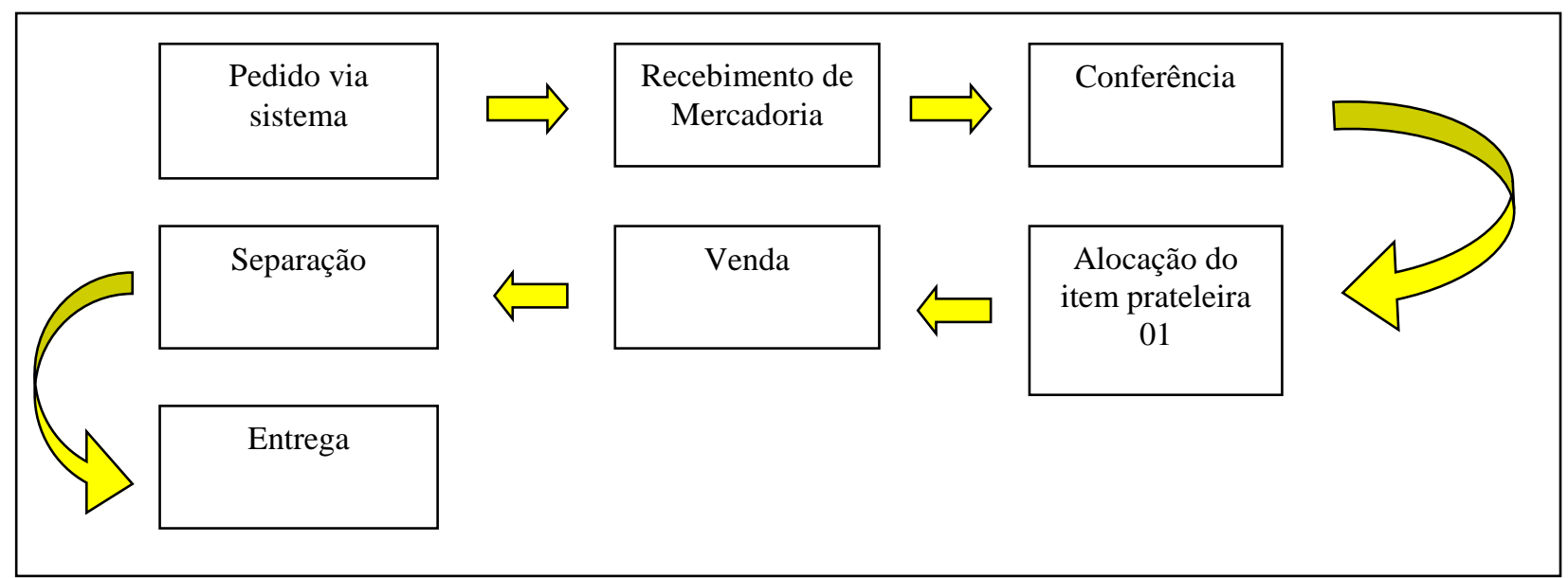

Figura 3. Fluxo dos Produtos em 2019.

Fonte: Dados da pesquisa (2019).

A partir da Figura 3, verificam-se os procedimentos dos itens no estoque da empresa, tais como o pedido das peças, recebimentos dos produtos, conferência, alocação nas prateleiras do estoque, o procedimento de vendas, separação e entrega dos itens. Ainda, a figura apresenta a sugestão de compra da empresa, uma ferramenta que auxilia na gestão dos estoques com a compra de produtos, evitando assim compras desnecessárias.

A seguir, a Tabela 5 expõe dados sobre as sugestões de compras.

Tabela 5

Sugestão de compra

\begin{tabular}{llcc}
\hline Código & Descrição & Quantidade mínima & Quantidade máxima \\
\hline MB5A/5W30/BA/ & Óleo lubrificante & 12.732 & 25.464 \\
EM5G/6714/AA/ & Filtro lubrificante & 1.656 & 3.312 \\
AM55/9155/AB/ & Filtro combustível & 1.502 & 3.004 \\
E3B1/1130/BA/ & Velas ignição & 86 & 172 \\
BE8Z/8124/A/ & Calota & 79 & 158 \\
W714040/S3/00 & Retentor & 29 & 58 \\
DG9Z/2078/D/ & Protetor caçamba & 29 & 58 \\
\hline
\end{tabular}

Nota. Fonte: Dados da pesquisa. 
Análise de Custos em uma Instituição de Ensino Superior: um Estudo Aplicado no Instituto Federal do Tocantins Samara Oliveira Alves, William Brasil Rodrigues Sobrinho

Após análise das curvas $A B C$, identificou-se a sugestão de compra com código, descrição, quantidade mínima de compra e quantidade máxima a ser pedido junto aos fornecedores. Esta tabela auxilia o comprador gerenciar suas compras de maneira que sejam mais objetivas e certeiras, evitando-se assim estoques obsoletos e diminuindo o custo das compras.

Depois de realizada a pesquisa pelo método de curva $A B C$, pôde-se implementar um novo procedimento para o setor de peças no qual o pedido é realizado através de um programa online, onde o vendedor preenche os campos com os dados do cliente, veículo e peça.

O recebimento das mercadorias e conferência continuaram os mesmos, mas a alocação dos itens foi alterada com a utilização da curva $A B C$ - em que o item da Figura 3 é o mesmo da Figura 2, e que anteriormente era alocado na prateleira 12 e passou a ser alocado na prateleira 01- para a otimização do tempo do estoquista; após a alocação dos itens, confere-se no programa através do código do item e encaminha-se um e-mail automático para o vendedor para verificar se o item está disponível para venda ou até mesmo atender o cliente.

\section{CONCLUSÕES}

O presente estudo buscou identificar como ocorre o controle de estoque, utilizando o método de curva $A B C$ em uma empresa do setor automobilístico. Inicialmente constatou-se que o método utilizado não era adequado e então se optou pela implementação do método $A B C$, pois esse se mostrou mais eficaz e eficiente gerando melhores resultados econômicos de custos e receitas.

Os procedimentos utilizados para a análise foram a pesquisa exploratória, analisando os produtos de maior rotatividade, estudo de caso e uma lista de checagem para qualificar os itens de grande, média e pequena importância para a empresa. A coleta dos dados foi realizada via sistema da empresa, onde se comparou o histórico de compras e vendas dos itens referentes ao ano de 2018. 
Análise de Custos em uma Instituição de Ensino Superior: um Estudo Aplicado no Instituto Federal do Tocantins Samara Oliveira Alves, William Brasil Rodrigues Sobrinho

Por meio da pesquisa realizada, obtiveram-se vários resultados, como itens com maior lucratividade, menor tempo de estoque e produtos obsoletos. Uma vez que o objetivo era realocar os itens com maior rotatividade no estoque através da curva $A B C$, empregou-se uma planilha para análise, onde se constou item, descrição, quantidade, custo unitário e custo total. Como a empresa nunca havia utilizado nenhum método de gerenciamento de estoques, foram identificadas várias falhas no departamento de peças, como os pedidos realizados, e, principalmente, a alocação dos itens sem nenhuma lógica ou organização.

Os resultados obtidos foram muito satisfatório na curva $A$ são 65 peças que possuem um grande giro anual, como no item óleo lubrificante que foi comercializado em 12.732 vendas. Através de uma análise das planilhas constatou-se que acurva A é formada por itens de revisões como óleo, filtros, cintas e fluídos. Na curva $B$, os itens de médio giro anual, como vela de ignição, com uma venda de 86 peças ao ano, e na curva $\mathrm{C}$, os itens com menor giro, como a peça isoladora vendida 29 vezes no ano. Foi realizada uma pesquisa das peças com maior custo total no ano, onde o item com maior valor desembolsado pela empresa no ano para aquisição foi o jogo de embreagem com um custo total de $\$ 177.457,68$.

Com a curva $A B C$, realocou-se as peças de acordo com sua importância, onde todos os itens que estavam na empresa foram alocados nas prateleiras para a otimização do tempo de separação do estoquista e melhor gerenciamento do estoque. Agora, com a curva $\mathrm{ABC}$, a empresa poderá comprar com maior segurança, sem receio de comprar peças desnecessárias e que podem virar obsoletas.

Através dos novos métodos de pedido de peças, via sistema online, há uma maior agilidade no atendimento aos pedidos de clientes como garantias e vendas, com isso, possibilitou satisfazer os clientes, já que o prazo de entrega das mercadorias diminuiu gradativamente. Isto é, no momento que chega a peça, o vendedor já recebe a informação que a peça está disponível e entra em contato com o cliente imediatamente.

Conclui-se que a curva $A B C$ é um método necessário para as empresas que têm estoques e não possuem nenhuma ferramenta de gerenciamento, pois ela auxilia na 
Análise de Custos em uma Instituição de Ensino Superior: um Estudo Aplicado no Instituto Federal do Tocantins

Samara Oliveira Alves, William Brasil Rodrigues Sobrinho

compra, alocação, venda e otimização de espaço e tempo, viabilizando redução de custos e melhoria do gerenciamento, sendo possível estabelecer metas importantes para o controle, a fim de otimizar os custos.

Para uma futura pesquisa será realizado um comparativo referente aos anos de 2018, onde não era utilizado nenhum método de gerenciamento de estoques e, no ano de 2019, em que foi implantado o método de curva $A B C$. Para que se possa ter uma pesquisa mais completa, pode-se identificar os custos totais do estoque e valores de mercado atualmente.

\section{REFERÊNCIAS}

Carvalho, C. J. (2015). Como a Gestão de Práticas de Oferta de Crédito Impacta a de Estoque. Revista de Administração Contemporânea, 19 (esp), 77-97.

Falchi, A. P. M., Francischetti, \& C. E., Lima, A. (2014). Estudo de aplicação de ferramentas de gestão de estoque visando a otimização de resultados: uma abordagem no setor público. Caderno Profissional de Administração da UNIMEP, 4 (2), 63-81.

Godinho, A. H., Canaldi, M. S., Garbin, S. T. A., \& Dutra, C. C. (2018). Controle interno de estoque-estudo de caso em empresa do ramo do comércio de peças automotivas de Caxias do Sul. Revista Global Manager Acadêmica, 6 (2), 606-621.

Gustavo, B., Domingos, A. P., \& Terra, A. A. R. T. (2013). A eficiência da gestão de estoques: estudo sobre a aplicação do lean manufacturing. Revista de Tecnologia Aplicada, 2 (2), 19-33.

Lemes, E. A., \& Lima, E. M. (2018). Análise dos Critérios Utilizados em Relação aos Estoques Obsoletos em uma Empresa Atacadista. Revista Mineira de Contabilidade, 19 (1), 68-79.

Lyra, A. S., \& Lazer, M. T. (2017). A importância do controle de estoque, utilizando o método de curva abc, em uma concessionária de veículos na cidade de BotucatuSP. Tekhne e Logos, 8 (4), 16-26.

Melo, J. C., \& Saito, A. T. (2016). Adequação das Práticas de Gestão de Estoques: o Caso de uma Microempresa do Setor de Móveis da Zona Norte de SP. Caderno Profissional de Administração da UNIMEP, 6 (2), 43-59. 
Oliveira, Renata Soares. (2018). Kanban e curva ABC: ferramentas de gestão estratégica aplicáveis a unidades hospitalares de abastecimento farmacêutico. $55 \mathrm{f}$. (Graduação em Farmácia). Escola de Farmácia, Universidade Federal de Ouro Preto, Ouro Preto, São Paulo.

Pinto, R. A. Q., Tortato, U., Veiga, C. P., \& Catapan, A. (2014). Gestão de estoque e lean manufacturing: estudo de caso em uma empresa metalúrgica. Revista Administração em Diálogo - RAD, 15 (1), 111-138.

Rabelo, M. H., \& Ventura, N. S. (2018). Gestão e Ferramentas de Estoque: estudo de caso realizado na casa de peças de uma concessionária da cidade de Luz-Minas Gerais. Revista Acadêmica Conecta FASF, 1 (3), 1-11.

Rodrigues, D. A., \& Carreira, M. F. (2018). Análise do custo e formação do preço de venda em um comércio de auto peças. Trabalhos de Conclusão de Curso do Departamento de Engenharia de Produção - DEP, Universidade Estadual de Maringá - UEM, Campus Sede, Paraná, Brasi 13 (1), 1-20.

Silveira, F., Nascimento, E. D. S., Rappeenthal, J. E., Machado, F. M., \& Ortiz, L. C. V. (2018). Estudo de caso do Sistema de Estoque Obsoleto de uma Concessionária de Caminhões do Noroeste do Rio Grande do Sul. Revista de Administração do Sul do Pará (REASP) - FESAR, 5 (1), 1-20.

Teixeira, J. A. (2016). Gestão de estoque: estudo de caso em uma concessionária Fiat no estado do Amazonas. 60 f. - Instituto CEUB de Pesquisa e Desenvolvimento, Centro Universitário de Brasília.

Vago, F. R. M., Sousa, C.V., \& Melo, J. M. D. (2013). A importância do gerenciamento de estoque por meio da ferramenta curva ABC. Revista Sociais e Humanas, Brasília, 26 (3), 638-655.

Wernke, R., Zanin, A., Schlickmann, L., \& Santos, A. P. (2017, junho). Custos financeiros da estocagem: estudo de caso em indústria de copos descartáveis. Congresso Internacional de Custos, Lyon, França, 15.

Data de Submissão: 21/02/2020

Data de Aceite: 21/07/2020 